Boston University School of Law

Scholarly Commons at Boston University School of Law

Faculty Scholarship

1986

Conflicts-of-Interest Disqualification in Medical Malpractice

Litigation

George J. Annas

Follow this and additional works at: https://scholarship.law.bu.edu/faculty_scholarship

Part of the Criminal Law Commons, Criminal Procedure Commons, and the Education Law Commons 


\section{Conflicts-of-Interest Disqualification in Medical Malpractice Litigation}

by George J. Annas, J.D., M.P.H.

L two decades ago it was thought sufficient to say, "When a practitioner is in doubt on an ethical question, the best answer is usually No." A more recent commentator has suggested, however, that "[s]uch plati. tudes have become increasingly inadequate to guide the attorney facing conflicts of interests in the private practice of law." 2 Because of the general vagueness of the American Bar Association's Model Code of Professional Responsibility, and of state codes based on it, courts have begun to fashion a vast "common law" of conflicts of interest. ${ }^{3}$ A particularly controversial entry to this body of common law is the opinion of Justice Paul Liacos, sitting as single justice in the Massachusetts case of Wbite $v$. Kaplan. ${ }^{4}$ This article examines the opinion and its theoretical support.

\section{The Facts}

Robert and Elaine White filed a malpractice suit against Dr. L. Fredrick Kaplan for his alleged failure to properly diagnose a tracheal tumor. At the September 1979 tribunal, Dr. Kaplan was represented by Attorney Peter C. Knight, and the Whites presented the expert opinion of Dr. Daniel Zoll in support of their suit. In January 1980 ,

Professor Annas is Utley Professor of Health Law at Boston University Scbool of Medicine and chief of the Health Law Section, Boston University Scbool of Public Health; chairman of the American Bar Association's Committee on Legal Problems in Medicine (Science and Technology Section); and editor-in-chief emeritus of Law, Medicine \& Health Care. Research assistance for this article was provided by Joan Densberger, a Boston College Law School student. (C) 1986 George J. Annas. in answer to interrogatories, the Whites again identified Dr. Zoll as their expert witness for trial.

In September 1980, Attorney Knight agreed to represent Dr. Zoll as defendant in an unrelated malpractice suit alleging that he negligently treated a foot wound caused by a piece of glass. In February 1982, Dr. Zoll's deposition was taken by the Whites' attorney (by this time Attorney Knight knew that he had undertaken to represent their expert witness in a separate matter). The Whites obtained new counsel for their suit in June 1983, and this attorney moved to disqualify Knight as the lawyer for Defendant Kaplan, on the basis that Knight had a conflict of interest in that he represented the Whites' expert witness in another malpractice matter. The trial judge thought he lacked the jurisdiction to compel defense counsel to withdraw, and the case was taken before Justice Liacos for resolution.

\section{The Opinion}

Justice Liacos sought to balance the interests of each party in a manner consistent with "the spirit of Canon 4" and "the perimeters of Canon 9" of the ABA Model Code of Professional Responsibility.

When explicit ethical guidance does not exist, a lawyer should determine his conduct in a man. ner that promotes public confidence in the integrity and efficiency of the legal system and the legal profession [EC 9.2]. ... Canon 4 states, "A lawyer should preserve the confidences and secrets of a client" and disciplinary rule 4-101(b) states, "a lawyer shall not knowingly use a confidence or secret of his client to the disadvantage of the client ... [or] use a confidence or secret of his client for the advantage of himself or of a third person unless the client consents after full disclosure."

Justice Liacos also cited Canon 9's injunction that "[a] lawyer should avoid even the appearance of professional impropriety" in order to protect the public's interest in the scrupulous administration of justice. ${ }^{7}$ He balanced these basic, but vague, principles against the litigant's right to the counsel of his choice.

Justice Liacos concluded that there were two possible ways in which the dual representation at issue might give rise to an unacceptable conflict of interest. Both involved the crossexamination of the client in his role as expert witness in the White case. One of two things might happen: "(a) the attorney may be tempted to use ... confidential information to impeach the witness; or (b) [the attorney] may fail to conduct a rigorous cross-examination for fear of misusing his confidential information."

This argument would have been stronger had there been some indication of what specific confidential information might have been involved, but Justice Liacos was content to note simply, in a footnote, that "while these cases may involve different bases for their respective claims, they both involve medical malpractice. The credibility, reputation and competence of both doctors will be in is sue at Dr. Kaplan's trial." Following this line of argument, Justice Liacos concluded that a breach of confidence need not be proven but only presumed, "in order to preserve the spirit of the code." ${ }^{10}$ In his words: "It is difficult to see how Mr. Knight could avoid, even unconsciously, the use of information acquired because of the attorney-client relationship 
with Dr. Zoll to impeach Dr. Zoll's credibility." "

Two other issues were considered: the defense of consent and the use of disqualification as a litigation tactic. Justice Liacos dismissed the consent defense by giving more weight to the "public trust in the notions of fundamental fairness and justice, and in the integrity of the bar." ${ }^{2}$ The justice saw the possibility that Dr. Kaplan would gain "an unfair advantage" as especially troublesome, and viewed disqualification as the appropriate rem. edy to protect the public's "faith in justice." ${ }^{13}$ Likewise, although recognizing the costs to all parties of using disqualification as an offensive weapon, Justice Liacos again concluded that protection of the "integrity of our judicial system" was an interest to which "Dr. Kaplan's right to counsel" must yield. ${ }^{1+}$ In a footnote, Justice Liacos suggested that $\mathrm{Mr}$. Knight should have withdrawn imme. diately as Dr. Kaplan's counsel upon learning of the conflict, in order to enable Dr. Kaplan to find substitute counsel, or should have "at least" informed the Whites so they could decide whether to continue to retain $\mathrm{Dr}$. Zoll as their expert. ${ }^{15}$

\section{Was Justice Liacos Right?}

Justice Liacos' opinion has been criticized on a number of grounds. The most important are that it is unprecedented; that it disregards the consent of Mr. Knight's clients to dual representation; that it takes little account of the client's right to choose his or her own lawyer; and that as a matter of efficiency, it would have been easier for the plaintiffs to obtain a new expert witness than for the defendant to obtain a new lawyer. The latter remedy, the critics contend, should have been pursued to discourage plaintiffs' attorneys from using disqualification as a tactic.

\section{The Precedents}

The basic model for conflicts of interest involves representing clients with conflicting interests, either in the same case or in different cases. Thus an attorney cannot represent both par ties (P1 and D1) in lawsuit A, or rep. resent one party in lawsuit A (P1) and the adverse party in lawsuit $A$ (D1) in lawsuit $\mathrm{B}$, or switch clients in lawsuit $\mathrm{A}$.

This traditional model was not, of course, at issue in White. Rather, here an attorney represented a party in

The aim of disqualification is not the retrospective sanctioning of the attorney or the granting of a new trial but the prospective protection of the integrity of the legal process itself.

lawsuit A (D1) and a completely different party in an unrelated lawsuit B (D2), who also happened to be an adverse witness to $D 1$ in lawsuit $A$. The generic question is: How close is this "adverse witness model" to the traditionally forbidden one? The answer depends on the ways in which the attorney could use his relationship with D2 to the advantage of D1 and, thus, to the unfair disadvantage of P1. Hypothetically, the attorney could use some confidential information gained from D2 in cross-examining D2 in lawsuit 1, to the advantage of $\mathrm{D} 1$ and the disadvantage of $\mathrm{P} 1$. Such use of confidential information would be unfair to P1 and would taint the adversarial process. Likewise, failure to conduct as vigorous a crossexamination of $\mathrm{D} 2$ as possible in law. suit 1 would disadvantage D1, and would evidence a "split of loyalties," again tainting the trial:

Conflicts of interest threaten to taint a trial in two ways, each of which upsets the adversarial balance. First, an attorney may turn confidences acquired in the representation of his present adversary to unfair advantage for his client. Sucb conduct too closely parallels the proscribed direct contact between the attorney and bis client's adversary. Second, conflicts of interest mar the adversarial process by leading to split loyalities which in turn result in the inadequate representation of one or more parties. ${ }^{16}$
In short, it was only a matter of time before this particular potential conflict came before the courts, and it should not be surprising that Justice Liacos treated it more like the traditional conflict model than like a nonconflict situation. Indeed, he could have made an even stronger argument by discussing the Code's similar rule against an attorney directly contacting a client of opposing counsel. ${ }^{17}$

If White had been a disciplinary action or a motion for a new trial in a criminal case, one could reasonably insist on evidence of actual prejudice or unfairness to the client. In a disqualification decision, however, the potential for such prejudice or unfairness is sufficient to justify judicial action, because the aim is not the retro spective sanctioning of the attorney or the granting of a new trial but the prospective protection of the integrity of the legal process itself. ${ }^{18}$ Thus it is not a fatal flaw in the opinion that no specific evidence of misconduct or prejudice was presented.

\section{Consent as a Defense}

The ABA's code of professional responsibility provides a basic exception to forbidden dual representations. If it is "obvious" that the attorney can adequately represent the interests of both, and if each client consents after "full disclosure," the attorney may engage in dual representation. ${ }^{19}$ The August 1983 ABA Model Rules restate the application of the consent exception to dual representa tion. A lawyer cannot represent two different clients unless:

1) The lawyer reasonably believes the representation will not adversely affect the relationship with the other client; and

2) Each client consents after consultation. ${ }^{20}$

The commentary to the new model rule explains that its wording is de. signed to clarify the consent and "obvious" requirements by allowing dual representation with consent if "the representation reasonably appears not to be adversely affected by the lawyer's other interests." ${ }^{21}$ The 
drafters believed they were simply restating the current requirement.

Justice Liacos' opinion can be approached from either of two roads, which converge at the same destination. The first interpretation is that he simply found that the representation in this case "reasonably appear[ed]" to affect the lawyer's other interests adversely, and thus concluded that client consent was insufficient to permit the conduct. The second interpretation, traveling a somewhat longer road, is that Justice Liacos specifically adopted the fiduciary model (by which professionals have independ. ent obligations to clients), as opposed to the contract model (by which the parties deal with each other on an equal basis at "arm's length"), in in. terpreting the ABA's canons. Under the fiduciary model it is impermissible for an attorney even to ask a client to consent to certain things. Consenting to this type of arrangement may be seen as one, forbidden as against public policy.

There is an analogy to this view of consent in medicine. We permit patients to consent to therapeutic modalities that are accepted medical practice; but although necessary, the patient's consent is not sufficient in human experimentation. In order to protect patients in general, and the integrity of the research enterprise in particular, we also require that the experiment itself be "reasonable" and, often, that it be independently re. viewed and approved by an institutional review board (IRB). ${ }^{22}$ We add these requirements to consent to permit human experimentation (rather than simply outlaw it) because we believe that experimentation is essential to medical progress, and because medical progress is highly valued by society.

In the adversary system, on the other hand, it is not essential that a particular person be represented by a particular attorney if that attorney has a potential conflict of interest. Thus we can protect both the client and the system's integrity by forbidding certain dual representations outright. "Because the attorney owes fiduciary duties to his client," one commentator notes, "the profession can and should place limits on the power of the client to waive his rights beyond a minimum level of effective assistance and attorney loyalty." 23 We can question the point at which Justice Liacos drew this imaginary line of impropriety, but the appropriateness of drawing the line itself is not at issue. The crux of the matter turns on the weight we attach to the interest of the client in choosing his or her own law. yer.

\section{Choice of Counsel}

The client's right to choice of counsel is an important value and, in a strict contract model of lawyer-client relationships, would determine the outcome. In a fiduciary model, however, choice of counsel must be limited to counsel without conflicts of interest, to prevent taints to the system. In the specific area under considerationdefense counsel in medical malprac. tice suits-the issue of counsel selec. tion is actually of only minor relevance. As noted Boston defense lawyer Douglas Danner comments in his Medical Malpractice: A Primer for

Pbysicians, written for physicians who are being sued for malpractice:

The typical malpractice insurance policy gives the insurance company the right to select counsel and control the defense. It will select attorneys it knows to bave experience and expertise in problems of medical malpractice defense. You should trust your defense counsel's advice. ... In a very real sense, regard yourself as the "patient" and allow your lawyer to assume the role you usually take. Try to conduct yourself as you would have any patient do-give your lawyer your respect and trust, listen well, provide all needed information, follow his protocol and don't try to do his job or "treat" yourself. ${ }^{2-4}$

Two points deserve emphasis. Since the insurance company, not the physician, has the right to select counsel, the individual's right to select his or her own counsel does not even come into play. To the extent that the insurance company can be seen as having a right to choose a par ticular lawyer for a particular case, this expectation should be outweighed by the necessity of protecting the system's integrity. Second, if it is typical of defense counsel to ask their clients to act like "patients" and "trust" them to do what is right, it can reasonably be argued that medical malpractice defense lawyers should have an even higher fiduciary duty to avoid potential conflicts of interest than do other lawyers. Indeed, their fiduciary responsibilities should be similar to those of physicians; the trust relationship with their clients should impose high obligations re lated to full disclosure and actions consistent with protecting the integrity of the legal system itself. Accordingly, Justice Liacos' cryptic comment that both the lawsuits at issue in Wbite "involve medical malpractice" may be much more telling than appears on the surface.

\section{Remedies}

There is no question that allegations of conflict of interest violations have become "common tools of litigation" and that such allegations are capable of "creating delay, harassment, additional expense, and perhaps even [of] resulting in the withdrawal of a dangerously competent counsel." 25 The application of Justice Liacos' opinion will likely serve to add fuel to this already brightly burning fire. Removal of an attorney from a case is, of course, unjustified when the conflict of interest issue is raised for purely tactical reasons. ${ }^{26}$ On the other hand, where the issue goes to the integrity of the trial itself, as Justice Liacos believed it did in White, removal is appropriate: "A trial exemplifies 'proce. dural justice': The legitimacy of the result in large part inheres in the process by which that result is achieved. When a conflict of interest threatens to 'taint the process,' the legitimacy of the trial is potentially undermined, a consideration that weighs heavily in favor of disqualification." 27

The alternative of requiring the plaintiff to obtain another expert is no alternative at all. It is not the plain. tiff's lawyer who has engaged in the challenged practice, and it is not ap 
propriate to penalize the plaintiff for the defense counsel's conflict of in. terest.

\section{Conclusion}

The result of White $v$. Kaplan is sound, although Justice Liacos could have articulated his rationale more precisely and convincingly. It is likely that the Massachusetts Supreme Judi cial Court will follow this opinion and expand upon it, should a similar case reach its docket. The case does present a problem for medical malprac. tice defense lawyers, but it is hardly an insurmountable one. Since lawyers are usually chosen by insurers, those insurers can designate another counsel with little prejudice as long as their lawyers keep adequate records of their representation of physicians in other relevant matters.

Disqualification can be harsh, but it is much less harsh than disciplinary action. Thus one can consistently conclude that even though no disciplinary action was warranted in White, disqualification was appropriate to protect the integrity of the bar and of the judicial system. White $v$. Kaplan can be seen as an impressionistic ba. rometer measuring the bench and bar view of the appropriateness of ethical regulation, and its responsiveness to reasonable, if debatable, judicial regulation. A positive response is called for lest "the profession's efforts at reg ulating itself . . . be seen as hollow doubletalk, creating safeguards that protect clients in theory only." 28

\section{References}

1. J.P. Frank, The Legal Ethics of Louis D. Brandeis, Stanford Law Review 17:683, 709 (1965), quoted in Note, Developments in the Law: Conflicts of Interest in the Le. gal Profession, Harvard Law Review 94(6):1244, 1284 (April 1981) (hereinafter cited as Conflicts). The author wishes to acknowledge his heavy reliance on the analysis set forth in the Conflicts article in preparing this article. It is highly recom mended reading for those who wish to explore this topic in more depth.

2. Conflicts, supra note 1 , at 1284 . See also L.R. Patterson, The Function of a Code of Legal Ethics, University of Miami Law Review 35(4):695 (July 1981).

3. Conflicts, supra note 1 , at 1284

4. White t. Kaplan, S.J.C. No. 83-252 (1983) (Liacos, J.)

5. Id. at 5 .
6. Id.

7. ABA Model Code of Professional CONDUCT (hereinafter cited as MODEL

8. White $v$. Kaplan, supra note 4 , at 7

9. Id at 5

10. Id. at 7 .

11. Id.

12. Id.

13. Id. at 8

14. See id.

15. Id.

16. Conflicts, supra note 1 at 1476 (emphasis added). The procedural device of permitting the disqualification of an attorney on conflict of interest grounds only if this issue is raised by a former or present client has been severely criticized as a "bi nary standard" that is "inappropriate" and an "unfortunate rubric," because it fails to take into account that inadequate advocacy must be eliminated to preserve the integ. rity of the trial as a lawmaking process, and "ignores the court's role in policing egregious misconduct on the part of attor. neys practicing before it." Id. at 1480 . See Estates Theatres, Inc. v. Columbia Pictures Indus., 345 F. Supp. 93, 98 (S.D. N.Y. 1972): "When the propriety of professional conduct is questioned, any member of the Bar who is aware of the facts which give rise to the issue is duty bound to present the matter to the proper forum."

17. Model Code, supra note 7, at DR7104(A) (1).

18. Justice Liacos relied primarily on two cases for his Canon 9 analysis: Emle Industries, Inc. v. Patentex, Inc., 478 F.2d 562 (2d Cir. 1973) (lawyer who had previously represented Burlington Industries disqualified when he attempted to repre. sent Emle, a Burlington subsidiary, in litigation against Patentex; the matters at issue in the two suits were deemed to be "substantially related" and the court found the invocation of Canon 9 "particularly appropriate"); Hull v. Celanese Corp., 513 F.2d 568 (9th Cir. 1975) (in-house counsel for Celanese switched sides to become a plaintiff-rather than an attorney-for the other side in the same litigation; the court held that Canon 9 prohibited the switch even though there was no evidence that any confidential information had been transmitted, because such information $m i g h t$ be transmitted and "the breach of confidence would not have to be proved; it is presumed in order to preserve the spirit of the Code"). Even though the drafters of the Model Rules rejected the Canon 9 goal of avoiding "the appearance of impropriety" as a disciplinary standard,
CODE), Canon 9. the courts will likely continue to consider it as a factor in determining whether an attorney ought to be disqualified. Courts have the power to disqualify lawyers (even absent proof of an ethical violation) in order to protect the parties or to maintain the integrity of the bar and the judicial system. N.J. Moore, Conflicts of Interest in the Simultaneous Representation of Multiple Clients: A Proposed Solution to the Current Confusion and Controversy, TeXas Law Review 61(2):211, 228-29, n. 93 (Oct. 1982)

19. MODEL CODE, supra note 7, at DR 5 . 105(C).

20. ABA Model Rules of Professional. CONDUCT, Rule 17(a).

21. ABa Model Rules of Professional. ConduCt AND CODE OF Judicial Conduct, August 1983, at 33 (emphasis added).

22. See G.J. AnNas, L.H. Glantz, and B.F. KATZ, INFORMED CONSENT TO HUMAN EXPERIMENTATION (Ballinger, Cambridge, Mass., 1977), 42-54. And see Note, The Client's Right to Consent to Potential Conflicts of Interest, CAPITAL UNIVERSITY LAW REVIEW 11(3):625 (Spring 1982); and Comment, Dual Representation in Unrelated Matters Can Protect Client's Best Interests, WasHINGTON UNIVERSITY LAW QUARTERLY 60(3):1155 (Fall 1982).

23. Conflicts, supra note 1 at 1305.

24. D. Danner, Medical Malpractice: A Primer for Physicians (Lawyers Co-operative Publishing Co., 1984) at 11 (emphasis added).

25. Conflicts, supra note 1 at 1285.

26. Id. at 1472 .

27. Id. at 1475 .

28. Id. at 1503. See Borman v. Borman, 393 N.E.2d 847 (Mass. 1979):

[T] he code is self-executing. We expect lawyers to know and comply with its provisions. If an attorney is unsure whether in a given case his conduct violates the code, he should terminate the questionable conduct or seek the advice of the appropriate Committee on Ethics and Professional Responsibility. If he persists in questionable conduct he risks disciplinary action including disbarment. When a lawyer, exercising his best judgment, determines that his employment will not bring him into conflict with the code, disqualification may occur only if the trial court determines that bis continued participation as coun. sel taints the legal system or the trial of the cause before it. (Id. at 856 [emphasis added].) Permitted with Client Consent When Firm

For further reading on strategies for avoiding conflict of interest, see Meibeyer, Hidden Conflicts, California Lawyer 5(5):27 (May 1985); Bush, Conflict of Interest: How to know It When You See It (and How to Get Out), Arizona Bar Journal 20(4):32 (Dec./Jan. 1985); Underwood, The Doctor and His Lawyer: Conflicts of Interest, Defense Law Journal 32(1):24 (1983); Countryman, A Systems Approach to Conflicts, Legal Economics 8(6):27 (Nov./Dec. 1982) (computer-based avoidance systems); Dondanville, Defense Counsel Beware: The Perils of Conflicts of Interest, THE FORUM 18(1):62 (Fall 1982) (defense counsel in insurance cases). 